This item was submitted to Loughborough's Research Repository by the author.

Items in Figshare are protected by copyright, with all rights reserved, unless otherwise indicated.

\title{
Interaction of clothing and thermoregulation
}

PLEASE CITE THE PUBLISHED VERSION

http://dx.doi.org/10.1159/000068802

PUBLISHER

(c) S. Karger AG, Basel

VERSION

AM (Accepted Manuscript)

LICENCE

CC BY-NC-ND 4.0

REPOSITORY RECORD

Havenith, George. 2019. "Interaction of Clothing and Thermoregulation". figshare.

https://hdl.handle.net/2134/12482. 
This item was submitted to Loughborough's Institutional Repository (https://dspace.lboro.ac.uk/) by the author and is made available under the following Creative Commons Licence conditions.

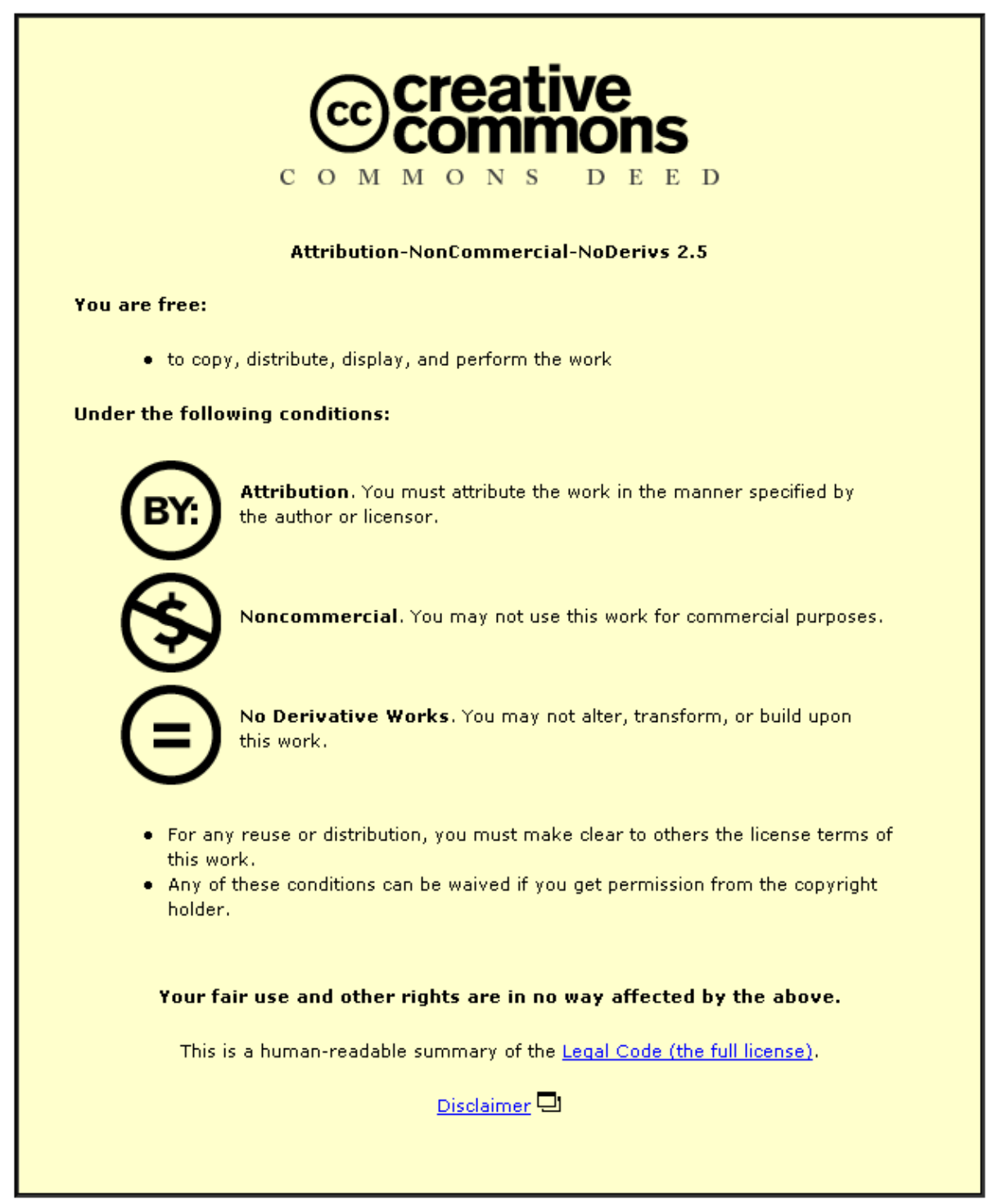

For the full text of this licence, please go to: http://creativecommons.org/licenses/by-nc-nd/2.5/ 


\title{
Havenith, G. (2002) The interaction between clothing insulation and thermoregulation; Exogenous Dermatology, 1(5) 221-230, 2002
}

\author{
Human Thermal Environments Laboratory \\ Department of Human Sciences, \\ Loughborough University, LE11 3TU
}

Version 2002-06-10

For

Exogenous Dermatology

Short title: Clothing and Thermoregulation

Dr. George Havenith

Human Thermal Environments Laboratory

Department of Human Sciences,

Loughborough University,

Ashby Road

Loughborough, UK

LE11 3TU

Phone +44 1509223031

Fax: +44 1509223940

Email: G.Havenith@lboro.ac.uk

Keywords: clothing, skin, thermoregulation, heat, cold, comfort, vapour, clothing, resistance, movement, wind, standards, models, stress, strain 


\section{Abstract}

Human temperature regulation is based upon a physiological system 'designed' for a naked person. Hence, the statement 'man is a tropical animal'. Human thermoregulation can be described as a feedback system with sensors in the body core and the skin, and effectors in the form of skin blood flow (vasoconstriction and dilation), metabolic activity (shivering), piloerection and sweating. This system on its own would provide some adjustment capabilities to various environments, but would nevertheless limit man to life in warm environments. It is the behavioural response that is the most powerful additional thermoregulatory effector in humans. People wear clothing, live in houses and have active heating and cooling systems to expand their habitat beyond the original physiological limits.

Clothing is an important interface between the human and the environment. Apart from the cultural meaning of clothing it provides insulation against cold, protection against sun, wind or rain as well as protection from other environmental hazards (chemicals, mechanical). The effect of clothing on thermoregulation depends in the first place on the textile materials used. These provide thermal insulation as well as resistance against vapour (sweat) transfer. However, a garment is more than just the textile layer. Air layers included in the clothing provide additional insulation and the total thermal protection provided by a garment is for a large part based on these enclosed air layers and strongly influenced by the clothing design and fit. Clothing comfort is determined by a number of clothing properties that affect the thermal conditions at the skin. Skin temperatures and the tactile sensation of the skin (e.g. sticky moist clothing) are the main signals that are fed to the brain and lead to an overall sensation of comfort or discomfort. 


\section{Introduction}

In terms of temperature regulation, humans are considered tropical animals. Our Physiological and anatomical systems are 'designed' for life in moderate and warm environments. There, we can maintain our bodily functions, and especially thermoregulation, without artificial means. However, when temperature goes down below $20^{\circ} \mathrm{C}$, we cannot sustain our body temperature in the long run without behavioural adjustments that include putting on clothing or using heated dwellings [1]. In this context, clothing has allowed humanity to expand its habitat around the world and has had a positive influence on its development.

Clothing is not only worn for temperature regulation, however. A strong cultural aspect is present as well, which actually can be counterproductive to thermoregulation. A business suit for instance is hardly functional in a tropical climate, nor is a ladies evening dress in a cold environment. Also, when the function of the clothing is not only protection against heat or cold, as e.g. is the case with chemical protective clothing, a conflict between the protective function of the clothing and the thermal functioning of the body may be present [2]. These conflicts can lead to discomfort, but also to physical strain and in extreme cases can put the person at risk from heat or cold injury or illness.

In order to understand these relations and conflicts, we first need to look at the process of body temperature regulation and of the body's heat exchange with the environment.

\section{Regulation of Body Temperature}

In a neutral climate, at rest, the human body regulates its temperature around $37^{\circ} \mathrm{C}$. This is by no means an exactly fixed temperature for all humans. When measured in the morning after bed-rest, the mean will be around 36.7 , with a standard deviation of $0.35^{\circ} \mathrm{C}$ (Fig. 1). During the day, the temperature will increase (typically by $\pm 0.8^{\circ} \mathrm{C}$ ), peaking in the late evening, and declining again until early morning due to the circadian rhythm. Also, exercise will cause an increase in body temperature, with temperatures around $38^{\circ} \mathrm{C}$ typical for moderate work and values up to 39 and occasionally above $40^{\circ} \mathrm{C}$ for heavy exercise (e.g. marathon). Increases up 
to $39^{\circ} \mathrm{C}$ are seldom a problem to the body and should be considered a normal phenomenon in thermoregulation $[4,5]$.

In fever, an increase in body temperature is observed as well. This increase differs from that in exercise in that the fever increase is defended by the body, whereas the exercise increase is not. Thus, when a fever of $38.5^{\circ} \mathrm{C}$ is present, cooling the body will lead to activation of heat conservation mechanisms by the body (shivering, vasoconstriction) to keep the temperature at that level. In exercise, the body would continue sweating until the body temperature is back to neutral levels.

Figure $1+2$ about here

An example of how the body's temperature regulation could be represented is given in Figure 2 . Here we have a body, which is represented by a body core temperature and by a skin temperature. Afferent signals representing these body temperatures are relayed to the control centres in the brain. There they are compared to a reference signal, which could be seen as a single thermostat setpoint, or as a number of thresholds for initiating effector responses. Based on the difference between actual temperature and the reference value (the error signal), various effector responses can be initiated. The main ones are sweating and vasodilation of skin vessels (if body temperatures are higher than the reference, i.e. a positive error) and shivering and vasoconstriction (negative error). Sweat evaporation will cool the skin, shivering will increase heat production and heat the core, and vasodilation and constriction will regulate the heat transport between core and skin.

Of course this is a simplified model, as many different thermosensitive regions of the body have been identified, and many different and more complex models are possible [6].

When we think of clothing we can think of it as an additional, behavioural effector response. We adjust our clothing levels to the climate we live in, providing the right amount of insulation to allow the other effector responses to stay within their utility range. The main effect of clothing 
will be its influence on the heat exchange between the skin and the environment. To understand these effects we will need to analyse the heat flows that exist between the body and its environment, in other words we have to look at the body's heat balance.

\section{Heat Balance}

When the body is not thermally stressed, its temperature is quite stable. This is achieved by balancing the amounts of heat produced in the body with the amounts lost. In these cases the heat storage rate is close to zero.

Heat production is determined by metabolic activity. When at rest, this is the amount needed for the body's basic functions, as e.g. respiration and heart function to provide body cells with oxygen and nutrients. When working however, the need of the active muscles for oxygen and nutrients increases, and the metabolic activity increases. When the muscles burn these nutrients for mechanical activity, part of the energy they contain is liberated outside the body as external work, but most of it is released in the muscle as heat. The ratio between this external work and the energy consumed is called the efficiency with which the body performs the work. This process is similar to what happens in a car engine. The minor part of the fuel's energy is actually effective in the car's propulsion, and the mayor part is liberated as waste heat. The body, as the car engine, needs to get rid of this heat; otherwise it will warm up to lethal levels. As an example: if no cooling would be present, a person working at moderate levels (metabolic rate 450 Watt) would show an increase in body temperature around $1^{\circ} \mathrm{C}$ every 10 minutes.

Figure 3 about here

For most tasks, as e.g. walking on a level, the value for the efficiency (in its physics definition) is close to zero. Only the heat released by friction of shoes etc. is released outside the body, whereas all other energy used by the muscles ends up as heat within the body. In the cold, additional heat is produced by shivering: muscle activity with zero efficiency. The basal metabolic rate and heat production can be increased up to fourfold in this way. 
For heat loss from the body, between skin and environment, several pathways are available (see Fig. 3 [1]). For each pathway the amount of transferred heat is dependent on the driving force (e.g. temperature or vapour pressure gradient), the body surface area involved and the resistance to that heat flow (e.g. clothing insulation).

$$
\text { Heat } \text { Loss }=\frac{\text { gradient } \cdot \text { surface area }}{\text { resistance }}(\text { watt })
$$

A minor role is taken by conduction. Only for people working in water, in special gas mixtures (prolonged deep-sea dives), handling cold products or in supine positions, conductivity becomes a relevant factor.

More important for heat loss is convection. When air flows along the skin, it is usually cooler than the skin. Heat will therefore be transferred from the skin to the air around it. Also heat transfer through electro-magnetic radiation can be substantial. When there is a difference between the body's surface temperature and the temperature of the surfaces in the environment, heat will be exchanged by radiation. Finally, the body possesses another avenue for heat loss, which is heat loss by evaporation. Due to the body's ability to sweat, moisture appearing on the skin can evaporate, with which large amounts of heat can be dissipated from the body.

Apart from convective and evaporative heat loss from the skin, these types of heat loss also take place from the lungs by respiration, as inspired air is usually cooler and dryer than the lung's internal surface. By warming and moisturising the inspired air, the body loses an amount of heat with the expired air, which can be up to $10 \%$ of the total heat production.

For body temperature to be stable, heat losses need to balance heat production. If they do not, the body heat content will change, causing body temperature to rise (positive storage) or fall (negative storage). This balance can be written as: 


$$
\begin{aligned}
\text { Store }= & \text { Heat Production }- \text { Heat Loss } \\
= & \text { (Metabolic Rate }- \text { External Work })- \\
& \quad(\text { Conduction }+ \text { Radiation + Convection + Evaporation + Respiration })
\end{aligned}
$$

It should be noted that several of the "heat loss" components might in special circumstances (e.g. ambient temperature higher than skin temperature) actually cause a heat gain, as discussed earlier.

\section{Relevant factors in heat exchange}

The heat exchanges listed above are dependent on a number of external parameters [1]:

\section{Temperature}

The higher the air temperature, the less heat the body can lose by convection, conduction and radiation. If the temperature of the environment increases above skin temperature, the body will actually gain heat from the environment instead of losing heat to it. There are three relevant temperatures:

- Air temperature. This determines the extent of convective heat loss (heating of environmental air flowing along the skin or entering the lungs) from the skin to the environment, or vice versa if the air temperature exceeds skin temperature.

- Radiant temperature. This value, which one may interpret as the mean temperature of all walls and objects in the space where one resides, determines the extent to which radiant heat is exchanged between skin and environment. In areas with hot objects, as in steel mills, or in work in the sun, the radiant temperature can easily exceed skin temperature and results in radiant heat transfer from the environment to the skin.

- Surface temperature. Apart from risks for skin burns or pain (surface temperature above $45^{\circ} \mathrm{C}$ ), or in the cold of frostbite and pain, the temperature of surfaces in contact with the body determines conductive heat exchange. Apart from its temperature, the surface's properties, as e.g. conductivity, specific heat and heat capacity, are also relevant for conductive heat exchange. 


\section{Air humidity}

The amount of moisture present in the environment's air (the moisture concentration) determines whether moisture (sweat) in vapour form flows from the skin to the environment or vice versa. In general the moisture concentration at the skin will be higher than in the environment, making evaporative heat loss from the skin possible. As mentioned earlier, in the heat evaporation of sweat is the most important avenue for the body to dissipate its surplus heat. Therefore situations where the gradient is reversed (higher moisture concentration in environment than on skin) are extremely stressful and allow only for short exposures. It should be noted that the moisture concentration, not the relative humidity is the determining factor. Air that has a relative humidity of $100 \%$ can contain different amounts of moisture, depending on its temperature. The higher the temperature, the higher the moisture content at equal relative humidities. When the air temperature is lower than the skin temperature, sweat will always be able to evaporate from the skin, even at $100 \%$ relative humidity.

\section{Wind speed}

The magnitude of air movement affects both convective and evaporative heat losses. For both avenues, heat exchange increases with increasing wind speed. Thus in a cool environment the body cools faster in the presence of wind, in an extremely hot, humid environment, it will heat up faster.

\section{Clothing insulation}

Clothing functions as a resistance to heat and moisture transfer between skin and environment $[1,8,9]$. In this way it can protect against extreme heat and cold, but at the same time it hampers the loss of superfluous heat during physical effort. E.g. if one has to perform hard work in cold weather clothing, heat will accumulate fast in the body due to the high resistance of the clothing for both heat and vapour transport. 
The way in which clothing affects heat and vapour transport will be dealt with in more detail below.

The environmental range for comfort, assuming no clothing or activity changes are allowed, is quite narrow. For light clothing with low activity levels it is around $3.5^{\circ} \mathrm{C}$ [10]. In order to widen this range, one has to allow for behavioural adjustments in clothing and activity. An increase in activity level will move the comfort range to lower temperatures, as will an increase in clothing insulation. E.g. an increase in metabolic rate of 20 Watts (resting levels are 100-160 Watts) pushes the comfort range down by approximately $1^{\circ} \mathrm{C}$, as does an increase in clothing insulation of 0.2 clo (clo is a unit for clothing insulation. For reference, a three-piece business suit is 1 clo; long trousers and short-sleeved shirt around 0.6 clo). An increase in air speed will push the comfort range up $\left(1^{\circ} \mathrm{C}\right.$ for $\left.0.2 \mathrm{~m} \cdot \mathrm{s}^{-1}\right)$.

In terms of physiological values, comfort can be related to skin temperature and skin wetness [11]. In Table 1, values for mean skin temperature, which are observed when, subject rate their thermal status as comfortable are listed. Typically, mean skin temperatures around $33^{\circ} \mathrm{C}$ are associated with thermal comfort. Also the relation between increasing skin wetness (the $\%$ of total skin area considered to be fully wetted, or expressed as the moisture evaporation from the skin in relation to that if the body were wet all over) and comfort is given. In the last columns, skin temperatures related to more extreme discomfort are presented ranging from those for frostbite risk to those for skin burns by heat exposure.

\section{Clothing and the Heat Balance}

Clothing acts as a barrier for heat and for vapour transport between the skin and the environment [12]. This barrier is formed both by the clothing materials themselves and by the air they enclose and the still air that is bound to its outer surfaces.

\section{Clothing materials}

Dry heat transfer through clothing materials consists mainly of conduction and radiation. For most clothing materials, the volume of air enclosed is far greater than the volume of the fibres. 
Therefore the insulation is very much dependent on the thickness of the material (i.e. the enclosed air layer) and less on the fibre type. The fibres mainly influence the amount of radiative heat transfer, as they reflect, absorb and re-emit radiation. That this effect is of minor importance relative to the thickness (except for special reflective clothing) can be seen in fig. 4 , where the insulation of a range of different clothing materials is presented in relation to their thickness.

Figure 4 about here

Thickness appears to be the major determinant of insulation [1,13]. For normal, permeable materials, clothing material thickness also determines the major part of the clothing vapour resistance. Again, as the volume of fibres is usually low compared to the enclosed air volume, the resistance to the diffusion of water vapour through the garments is mainly determined by the thickness of the enclosed still air layer. With thin materials, the fibre component gets a more important role as there e.g. different weave characteristics affect the diffusion properties more than in thick materials (Fig. 5).

Figure 5 about here

When coatings, membranes or other treatments are added to the fabrics, this will have a major effect on vapour resistance, where diffusion of vapour molecules is involved. The effect on heat resistance, where conduction is the main pathway within the fabric, of such treatments is much less.

The fibres of the clothing materials do determine other properties of the clothing like air permeability and moisture absorption however, which may affect insulation and vapour resistance in special conditions like high winds and wet environments. 


\section{Clothing ensembles}

When not only the materials are considered $[14,15]$ but the actual insulation of a material in a garment, or when the clothing consists of more layers, the properties of the air layers between and on the outside of the material layers become important [1]. Each material layer has a still air layer attached to its outer surface. This layer can be up to $6 \mathrm{~mm}$ thick $(12 \mathrm{~mm}$ total between two surfaces), outside of which the air is insufficiently bound and will move due to temperature gradients. Thus if we express the insulation or vapour resistance of a material in units of equivalent still air thickness (the thickness of a still air layer that has the same insulation or vapour resistance as the material studied) a $2 \mathrm{~mm}$ thick material could produce a resistance for heat or vapour transport over the body of 12+3+6 (trapped still air layer between skin and clothing + still air equivalent of material + still air layer at outside of clothing $)=21 \mathrm{~mm}$ still air equivalent. If the garment or clothing ensemble would consist of several material layers the total insulation will therefore be much higher than could be expected from the insulation of the material layer alone (Fig.6).

Fig. 6 about here

The total insulation of a garment will not add up to the number of layers multiplied by $15 \mathrm{~mm}$ (12 trapped +3 per layer), however. Due to clothing design, body shape and fit the layers will not be separated enough to enclose such thick air layers. At the shoulders e.g. the layers will be directly touching, and thus there the total insulation will only be the sum of the material layers plus one air layer on the outer surface. When the clothing fits tightly, less air will be included than when it fits loosely (Fig. 6). Also, the trapped still air layer of $12 \mathrm{~mm}$ mentioned above would not be reached when the garment isn't completely still, and when air movement (wind) is present.

Figure 7 about here 
Air movement. When the air in the environment is moving, as usually is the case at a workplace, this air movement will disturb the still layer on the outside of the clothing. Also this air movement can disturb the air layers in the ensemble, by entering through clothing openings or, depending on the air permeability of the outer clothing layer, by penetration of the clothing fabric. The effect air movement has on the outer air layer (or on a nude persons insulative air layer), is presented in Fig. 7.

Garment movement. The garment can move by the wind, or by movements of the wearer. The wind can compress the garments, thereby decreasing its thickness, it can make the garment flutter and thereby make the enclosed air layers move. Body movement of the wearer can do the same things, and it can pump air between different clothing compartments and force it's exchange with the environment (Fig. 8).

In general, motion has an effect on enclosed and surrounding air layers, whereas wind mainly affects the surrounding air layer and the layer under the outer garment.

Fig. 8 about here

The combined effect of wind and movement on garment insulation can be quite dramatic. For the clothing insulation, reductions by up to $60 \%$ have been observed due to walking in $4 \mathrm{~m} . \mathrm{s}^{-1}$ wind $[16,17]$. For vapour resistance, the effects were even larger due its purely convective nature $[18,19]$. Here reductions by up to $80 \%$ in vapour resistance were observed (Fig. 9)

Figure 9 about here

The effect clothing has on the heat balance is illustrated in Table 2. Here, for protective clothing with different properties in terms of heat and vapour resistance, the maximal exposure times for people performing moderate work are presented. It is evident, given these numbers, that clothing can reduce tolerance times dramatically.

The interaction between clothing properties and thermoregulation is further demonstrated in Fig. 10. This shows body core temperature and heart rate development over 90 minutes of work in a 
warm environment with light air movement for two protective clothing ensembles, which are identical except for the air permeability of the outer material. The graphs demonstrate how the higher air permeability alleviates the heat strain experienced by the person.

In addition, evidence has been presented that clothing will actually alter the thermoregulatory system's functioning. People have been shown to adapt physiologically to different clothing configurations, e.g. adding subcutaneous fat thickness to areas with consistently lower clothing insulation [21].

\section{Metabolic rate and clothing}

Clothing, apart from its effect on heat exchange, also affects metabolic rate. The weight of the clothing adds to body weight (for some protective clothing this is above $15 \mathrm{~kg}$ ) and as it is carried results in an increase in metabolic rate in activities as walking.

The weight distribution over the body becomes important in more elaborate clothing ensembles as e.g. chemical protective or NBC protective clothing. Weight on the torso or head is carried quite efficiently, but weight on hands and feet (e.g. boots) has a much higher impact per unit of mass. For the feet this can be over 5 times more per $\mathrm{kg}$ than on the torso. In such ensembles, also the stiffness plays a role and overcoming this stiffness in order to move leads to an additional increase in work effort and metabolic rate.

\section{Comfort and Clothing}

Comfort is a state of mind influenced by a range of factors, some physical, some physiological and some psychological. Thermal comfort, as a sub-set of overall comfort, is a complex sensation too, integrating various different sensory inputs. This sensation can be regarded as the driving force of behavioural thermoregulation. Typically, the sensation of heat or cold and that of humidity or skin wetness are the main determinants of overall comfort. Sensors in the skin register the temperature and the speed with which the temperature changes and these inputs, when relayed to the brain, will result in a temperature sensation. 
No sensors are available for a moisture or skin wetness sensation. Instead, this sensation is in part determined by the temperature sensors, sensing an increased cooling speed of wet skin, and by tactile sensors that sense sweat drops trickling down the skin. Our brain interprets this as a moisture sensation.

Clothing can amplify the sensation of wetness dramatically. Firstly, when the skin is wet and starts wetting the clothing, the latter becomes sticky and the friction between clothing and skin induces a strong tactile sensation that is interpreted as uncomfortable. Secondly, wet clothing cools down quickly. Typically during movement the clothing will move to and from the skin. When away from the skin it will evaporate moisture and cool down, which, when it touches the skin will induce a strong cold sensation, interpreted as wetness. Both aspects can be influenced by clothing design and material selection. The latter effect can be reduced by having tight fitting clothing at the skin and by using a low absorption material. The first effect can be reduced by selecting a material that has a fibre structure that will prevent it from direct skin contact over large areas. An example of clothing that had very bad properties in this respect were the early nylon/polyamide shirts, which had a low air permeability, trapping moisture at the skin, and had a very flat weave structure that easily stuck to the skin like a wet towel. Clothing that transports the moisture away from the skin, e.g. double layered fabrics with a moisture conductive but low absorption inside (polyester) and an absorptive (e.g. cotton) outside, has successfully improved comfort on this point [22].

An additional clothing property that can improve its performance in terms of comfort is the buffering capacity of heat and moisture. This is especially relevant under changing circumstances. E.g. when activity levels vary, as in many sports and leisure activities, peaks in sweating may be followed by periods of low sweat production. If clothing is able to buffer this sweat, the presence of liquid water on the skin may be prevented which would prevent the sticky feeling, prevent excessive cooling in less active periods (after chill), and improve comfort. This can be achieved by using material fibres that can absorb moisture well (natural fibres) or by using material treatments (hydrophilic) or special fibre structures (open canals in fibre), 
spinning and weaving techniques (trapping moisture between fibres or yarns), though as discussed earlier the moisture needs to be kept away from the skin.

The recent introduction of phase-change materials (materials containing substances that change their chemical structure at a certain temperature by absorbing or releasing heat, comparable to the phase change of water to ice and vice versa) has opened up the opportunity for buffering of heat in circumstances where people regularly move between different climates. With this buffering activity, they should reduce the climatic stress on the wearer and improve comfort. Unfortunately the currently available materials have only a small heat buffering capacity and substantial advantages have not yet been shown [23]. The technology is promising for the future, however.

\section{REFERENCES}

1. Havenith G: Heat Balance when Wearing Protective Clothing. Ann. Occup. Hyg. , 1999; 43, 5: 289296.

2. Medema J, Wittgen PPMM, Lotens WA and Havenith G: Investigations into the performance of NBCprotective overgarments. ReportTNO Prins Maurits Laboratory, PML 1988-C138

3. Wenzel C and Piekarsky HG: Klima und Arbeit, Bayrisches Staatsministerium fuer Arbeit und Sozialordnung, 1984.

4. Havenith G: Climate, Heat Balance, Heat Tolerance and Individual Differences. In: The Industrial and Occupational Ergonomics Users' Encyclopedia, Eds. Mital, A., Ayoub, M., Kumar, S., Wang, S-L., Landau, K.,Pennathur, A., Fernandez, J., Mehta, H., Chan, A.H.S., Chung,M.K., Coury, H.G., Hwang, S-L., Kumashiro, M., Nag, P.K., Rice, V., Ramsey, J.,and Sinclair, M.A., International Journal of Industrial Engineering, 1999, CD-ROM, ISBN 0965450600.

5. Havenith G: Temperature Regulation In The Elderly- Improving Comfort And Reducing Morbidity And Mortality Using Modern Technology. Gerontechnology, 1, sept 2001; 41-49.

6. Havenith G: An individual model of human thermoregulation for the simulation of heat stress response. J Appl Physiol, 90: 1943-1954, 2001.

7. Farnworth B: Materials and clothing design; Proceedings of the 5 th int. conf. on environmental ergonomics, Maastricht, nov. 2-6, 1992; eds. W.A.Lotens and G. Havenith . 
8. Umbach $\mathrm{KH}$ : Measuring the physiological properties of textiles for clothing, Melliand Textilberichte, 1980, 61, 747-757.

9. Havenith G: Clothing and Thermoregulation. in: Textiles and the Skin. Current Problems in Dermatology, Elsner, P., Hatch, K. and Wigger-Alberti W.(Eds). Karger Verlag, Basel, vol 31, pp 3539, 2002.

10. ISO 7730: Moderate Thermal Environments -Determination of the PMV and PPD indices and specification of the conditions for thermal comfort. Geneva, International Standardisation Organisation, 1984.

11. Havenith G, Holmér I, and Parsons K: Personal factors in thermal comfort assessment: clothing properties and metabolic heat production, Energy and Buildings 34 (6) (2002) pp. 581-591.

12. Mecheels J, Umbach $\mathrm{KH}$ : Thermophysiologische Eigenschaften von KleidungssystemenThermophysiological properties of clothing systems. Melliand Textilberichte 1976 vol 57 part 12 pp 1029-1032.

13. Lotens WA : Heat transfer from humans wearing clothing. Ph.D. Thesis, Delft University of Technology, February 1993, Delft 1993.

14. Kwon A, Kato M, Kawamura H, Yanai Y, Tokura H, Physiological significance of hydrophilic and hydrophobic textile materials during intermittent exercise in humans under the influence of warm ambient temperature with and without wind, Eur J Appl Physiol Occup Physiol, 1998, Vol.78, No.6, pp.487-493.

15. Ha M, Yamashita Y, Tokura H: Effects of two kinds of clothing with different properties for moisture on thermophysiological responses and heart rate during intermittent exercise at an ambient temperature of $24^{\circ} \mathrm{C}$; Proceedings 6 th International Conference on Environmental Ergonomics; Montebello, Quebec, Canada, 25 - 30 September 1994; editors: J. Frim, M.B. Ducharme and P. Tikuisis pp 92 -94

16. Havenith G, Heus R, and Lotens WA: Resultant clothing insulation: a function of body movement, posture, wind, clothing fit and ensemble thickness. Ergonomics 1990, 33: 67-84.

17. Holmér I, Nilsson H, Havenith G, Parsons KC: Clothing convective heat exchange - proposal for improved prediction in standards and models, Annals of Occupational Hygiene 1999; 43, 5: 329-337

18. Havenith G, Heus R, Lotens WA: Clothing ventilation, vapour resistance and permeability index: changes due to posture, movement and wind. Ergonomics 1999, 33: 989-1005.

19. Havenith G, Holmér I, Den Hartog EA, Parsons KC: Clothing evaporative heat resistance - proposal for improved representation in standards and models, Ann of Occup Hygiene 1999; 43, 5: 339-346. 
20. Havenith G, Vuister RGA and Wammes LJA : The effect of air permeability of chemical protective clothing material on the clothing ventilation and vapour resistance (in Dutch). Report TNO-TM 1995 A 63. TNO-Human Factors Research Institute, Soesterberg, NL.

21. Imamura $\mathrm{R}$, Funatsu $\mathrm{M}$, Kawachi $\mathrm{H}$, Tokura $\mathrm{H}$ : Effects of wearing long- and mini-skirts for a year on subcutaneous fat thickness and body circumference. In: Environmental Ergonomics IX, Werner, J. and Hexamer, M. (eds), Shaker Verlag GmbH, 9th International Conference on Environmental Ergonomics, Dortmund, Germany, August 2000, pp 205-208, ISBN 3826576489.

22. Umbach $\mathrm{KH}$, Comfortable clothing made from man-made fibres.Chemisfasern/ Textilindustrie 1983 vol 33/85 part 2 pp 136-139

23. Shim $\mathrm{H}$ and McCullough AE: The effectiveness of phase change materials in outdoor clothing; Arbete och Hälsa 2000, 8: 90-94. 
Figure 1, Individual body temperature distribution of a group of subjects; adapted from data of Wenzel and Piekarsky [3])

Figure 2, Schematic representation of the thermoregulatory control system. $\mathrm{T}_{\text {core }}=$ body core temperature; $\mathrm{T}_{\text {skin }}=$ mean skin temperature; brain controller graphs show reaction of effector (Y-axes) to error signal (X-axes) (adapted from [7]).

Figure 3, Schematic representation of the pathways for heat loss from the body. $\mathrm{M}=$ metabolic heat production [1].

Figure 4, relation between clothing material insulation and the material thickness (Havenith and Wammes, in [13])

Figure 5, relation between material vapour resistance and material thickness $[1,13])$

Figure 6, schematic representation of fabric and air layer contribution to total heat and vapour resistance [1]

Figure 7, effect of wind speed on insulation of surface air layer [13].

Figure 8, effect of motion and of wind on the surface and trapped air layers [1]

Figure 9, reduction in vapour resistance due to movement and wind for a chemical protective clothing ensemble. Vapour resistance is expressed in $\mathrm{mm}$ of still air equivalent [20].

Figure 10, effect of air permeability of a protective ensemble on the heat strain expressed as rectal temperature and heart rate, while working in a warm, windy environment [20] 
Table 1, body temperatures and skin wetness in relation to comfort and health $[1,4,13]$.

\begin{tabular}{|c|c|c|c|c|c|c|}
\hline $\begin{array}{c}\text { Body core } \\
\text { temperature } \\
\left({ }^{\circ} \mathrm{C}\right)\end{array}$ & Condition & $\begin{array}{c}\text { Mean skin } \\
\text { temperature } \\
\left({ }^{\circ} \mathrm{C}\right)\end{array}$ & $\begin{array}{l}\text { Comfort } \\
\text { sensation }\end{array}$ & $\begin{array}{c}\text { Skin } \\
\text { Wetness } \\
(\%)\end{array}$ & $\begin{array}{l}\text { Local Skin } \\
\text { temperature } \\
\left({ }^{\circ} \mathrm{C}\right)\end{array}$ & Condition \\
\hline 44 & $\begin{array}{l}\text { heat stroke, brain } \\
\text { damage }\end{array}$ & & $\begin{array}{c}\text { Very } \\
\text { Uncomfortable }\end{array}$ & 60 & $>45$ & $\begin{array}{l}\text { Skinburns, time } \\
\text { dependent }\end{array}$ \\
\hline \multirow[t]{2}{*}{41} & Fever therapy & 36 & & 40 & 45 & Pain \\
\hline & very heavy exercise & 35 & $\begin{array}{c}\text { Slightly } \\
\text { uncomfortable }\end{array}$ & 20 & & \\
\hline 38 & Exercise & 34 & & 6 & 25 & Cool \\
\hline 37 & $\begin{array}{c}\text { Normal resting } \\
\text { condition }\end{array}$ & 33 & Comfortable & & 20 & Reduced dexterity \\
\hline \multirow[t]{2}{*}{36} & & 32 & $\begin{array}{c}\text { Slightly } \\
\text { uncomfortable }\end{array}$ & & 15 & Pain \\
\hline & & 31 & & & 7 & Numbness \\
\hline 35 & Shivering & 30 & uncomfortable & & -0.5 & Frostbite \\
\hline $\begin{array}{l}33 \\
31\end{array}$ & $\begin{array}{c}\text { Reduced } \\
\text { consciousness } \\
\text { Ventricle fibrillation } \\
\text { "death" }\end{array}$ & & & & & \\
\hline 14 & $\begin{array}{l}\text { Lowest measured } \\
\text { temperature with full } \\
\text { recovery }\end{array}$ & & & & & \\
\hline
\end{tabular}


Table 2 time for a worker to reach a body temperature of $38.5^{\circ} \mathrm{C}$ in a $37^{\circ} \mathrm{C}$ environment performing moderate work in different clothing ensembles

\begin{tabular}{|c|c|}
\hline Clothing type & Maximal exposure time (min) \\
\hline Nude & 120 \\
\hline Normal work gear, cotton, single layer & 90 \\
\hline Protective clothing, cotton, 3 layers & 45 \\
\hline $\begin{array}{c}\text { Protective clothing, cotton, waterproof outer layer, total } \\
\text { 3 layers }\end{array}$ & 30 \\
\hline Fully encapsulating clothing, impermeable outer layer, & 20 \\
\hline
\end{tabular}




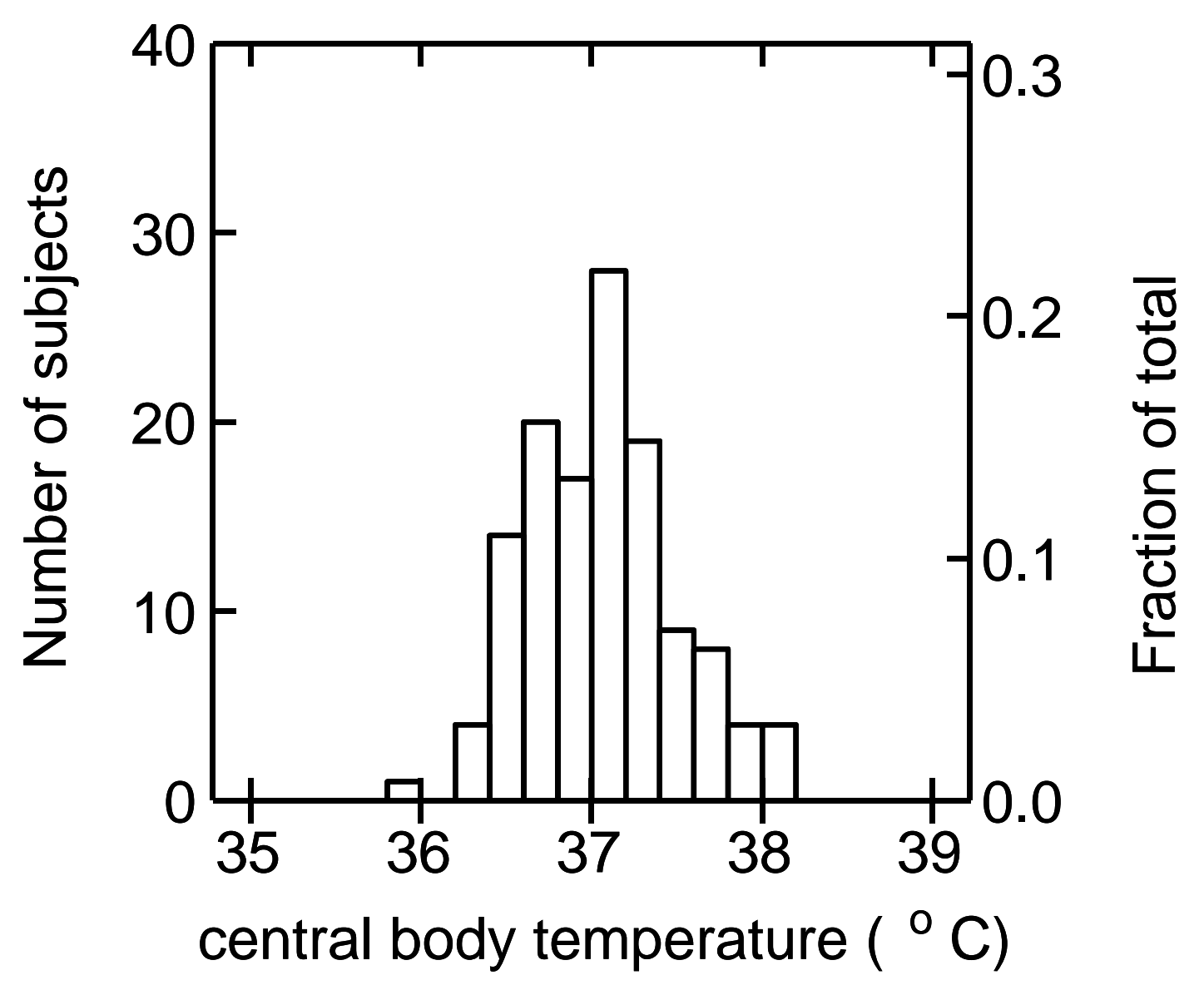

Heat Balance when wearing clothing, Figure 1 of 10 
Brain Controllers

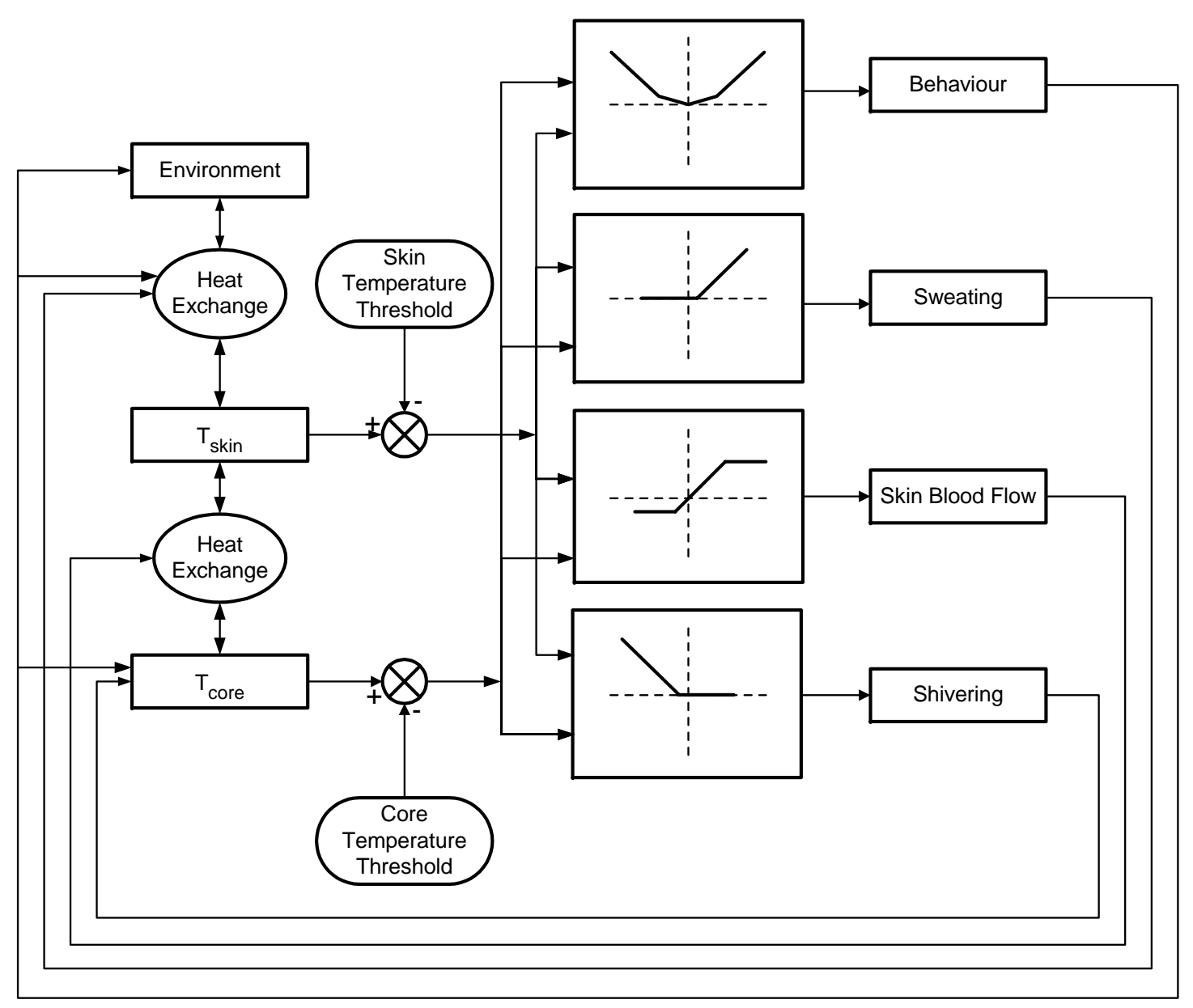




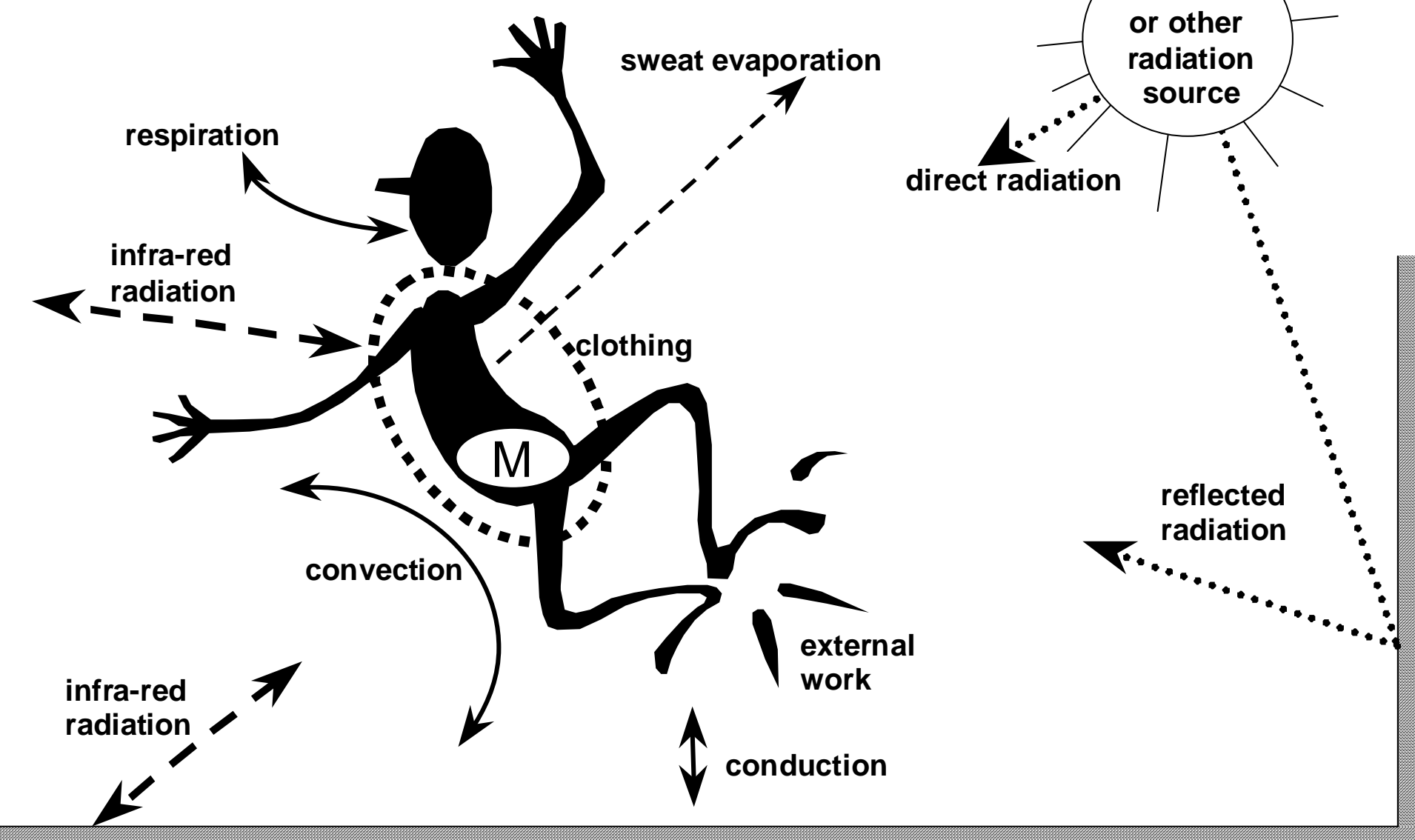




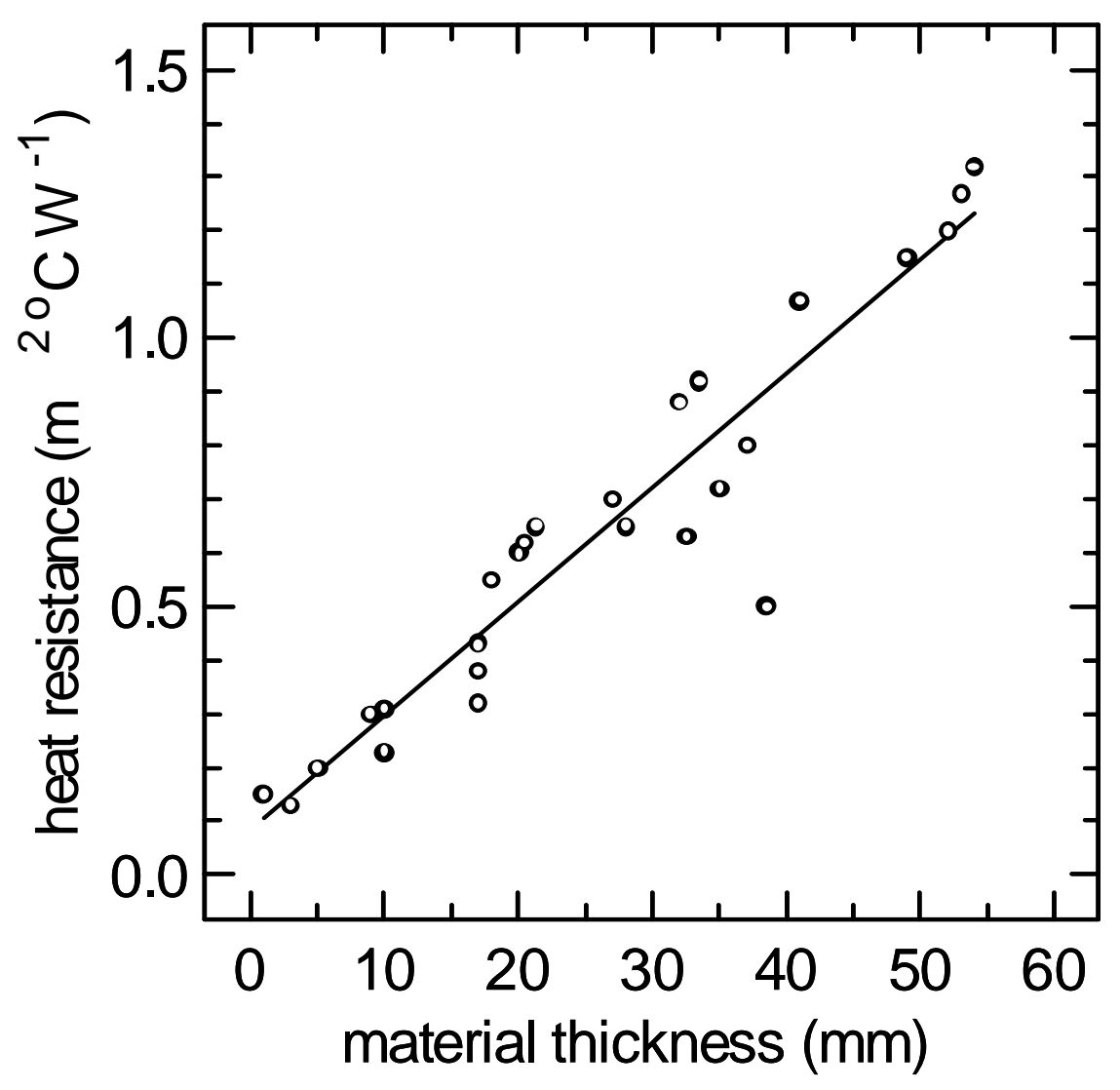

Heat Balance when wearing clothing, Figure 4 of 10 


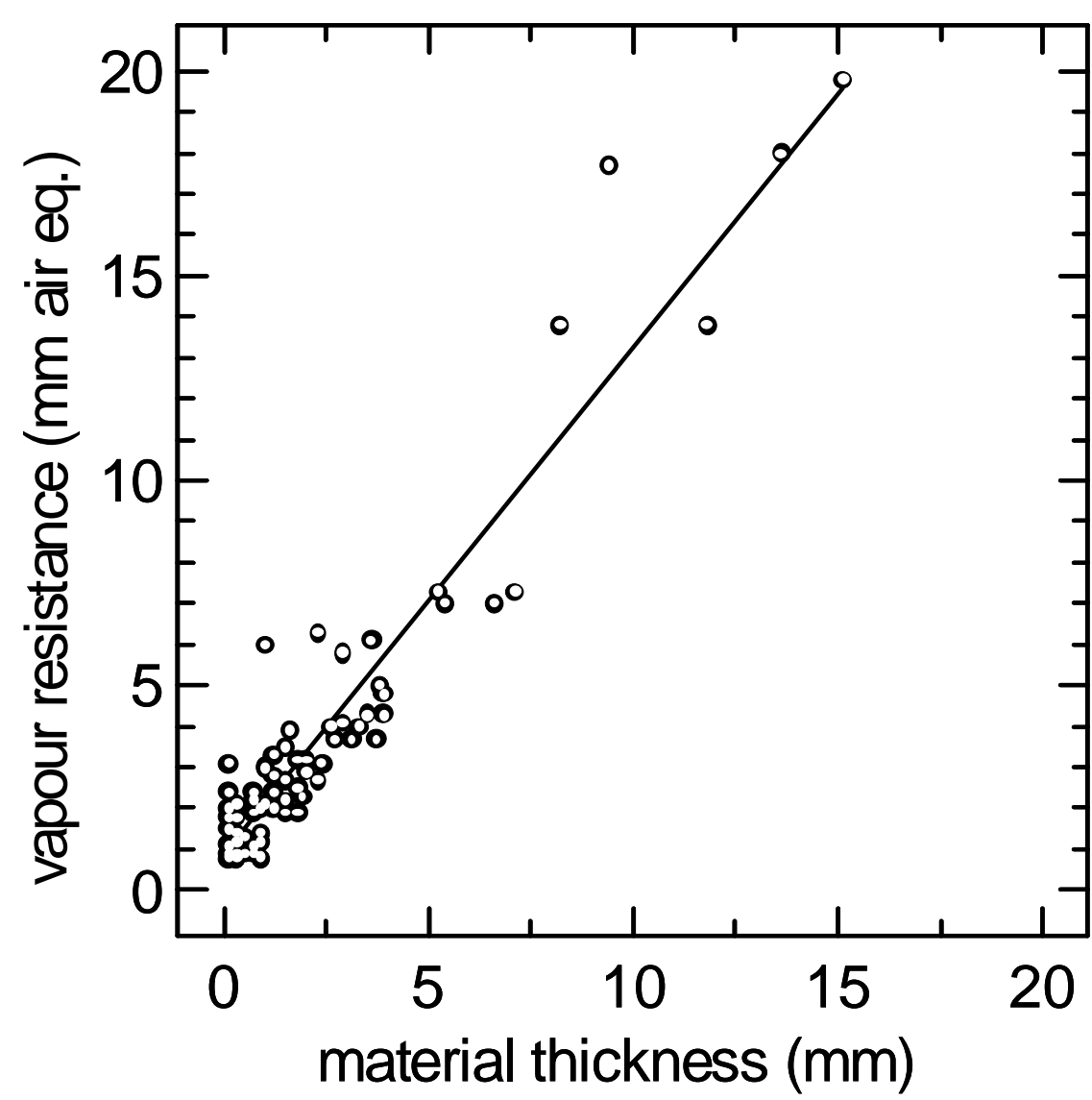

Heat Balance when wearing clothing, Figure 5 of 10 
still air $\longrightarrow$ vapour
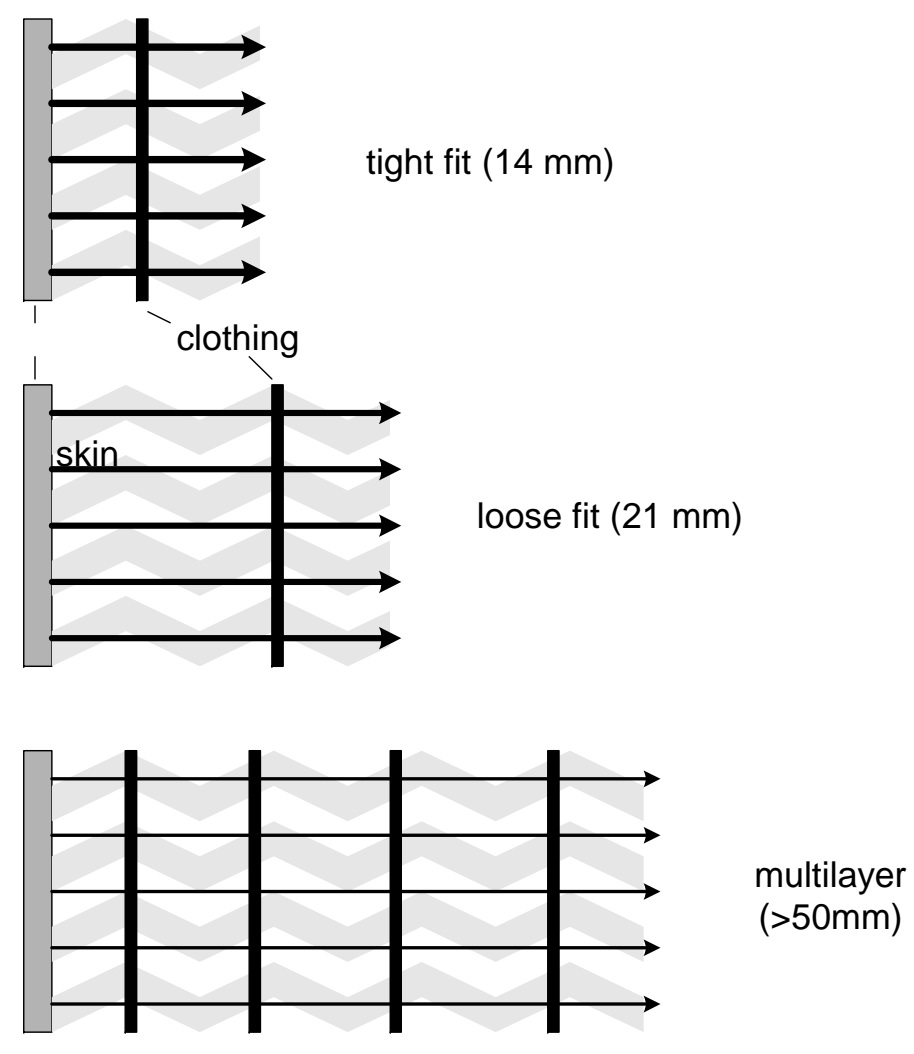


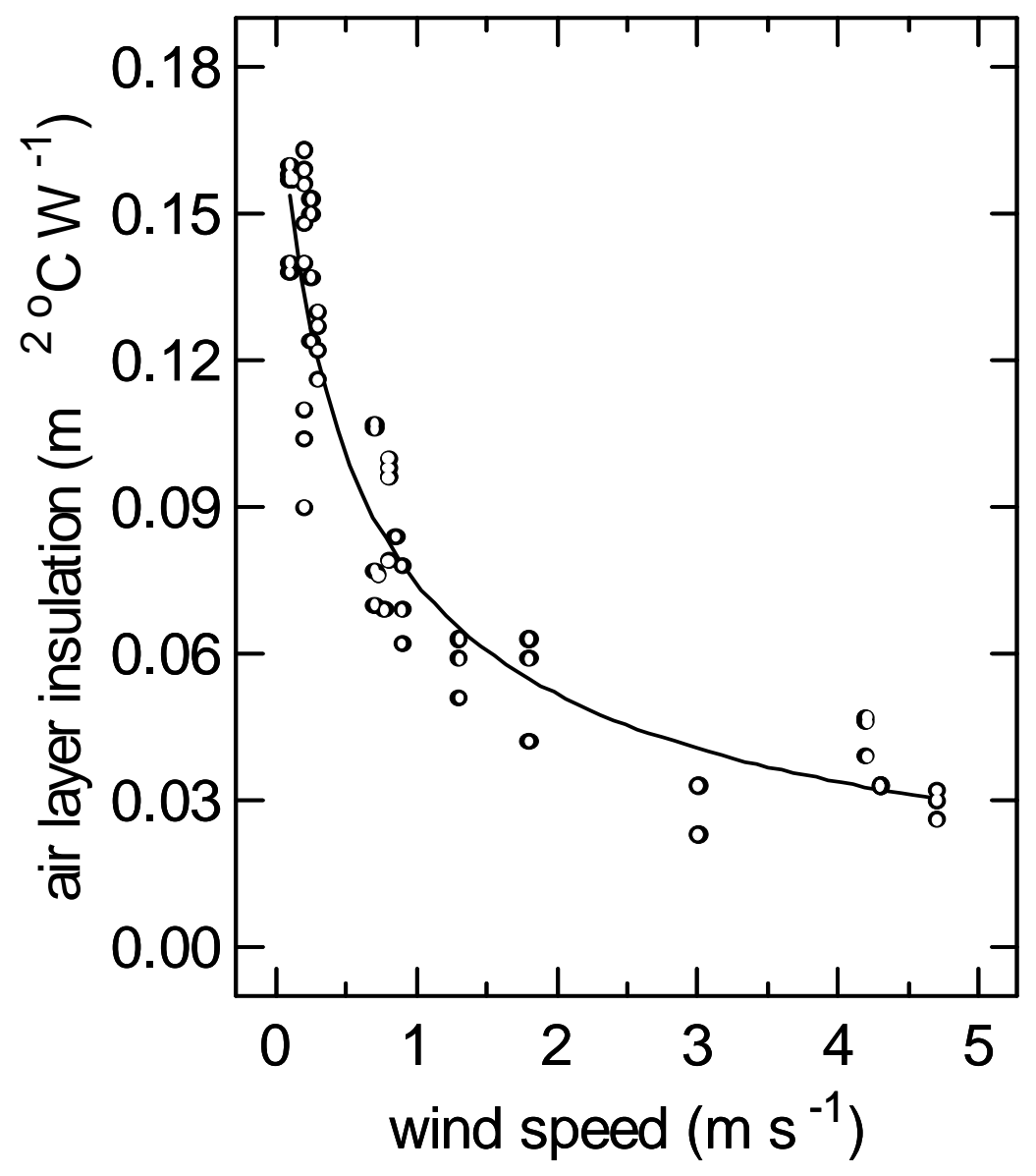

Heat Balance when wearing clothing, Figure 7 of 10 
still air $\longrightarrow$ vapour, heat

still air $\longrightarrow$ and air movement

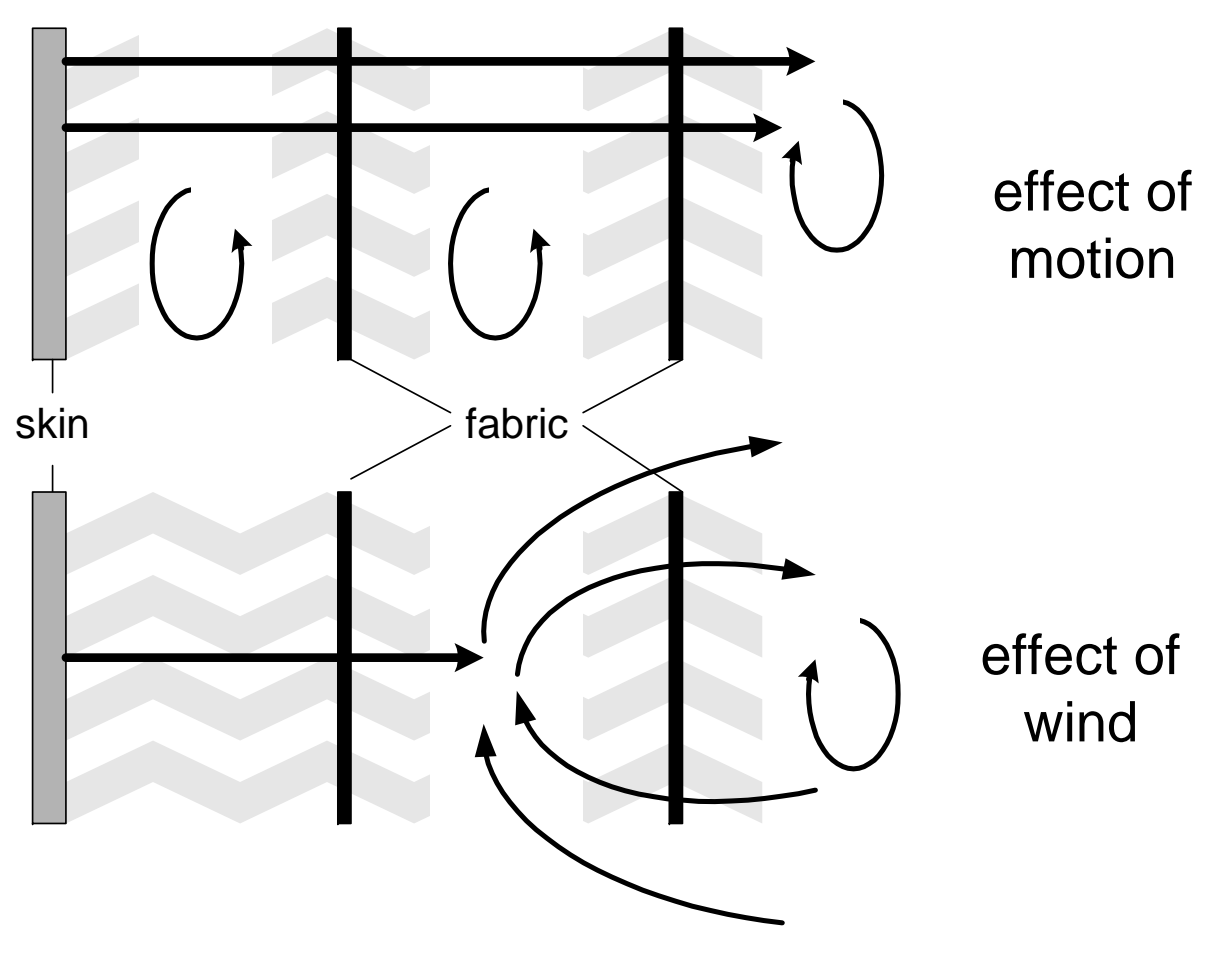

Heat Balance when wearing clothing, Figure 8 of 10 
this figure can be reproduced in black and white

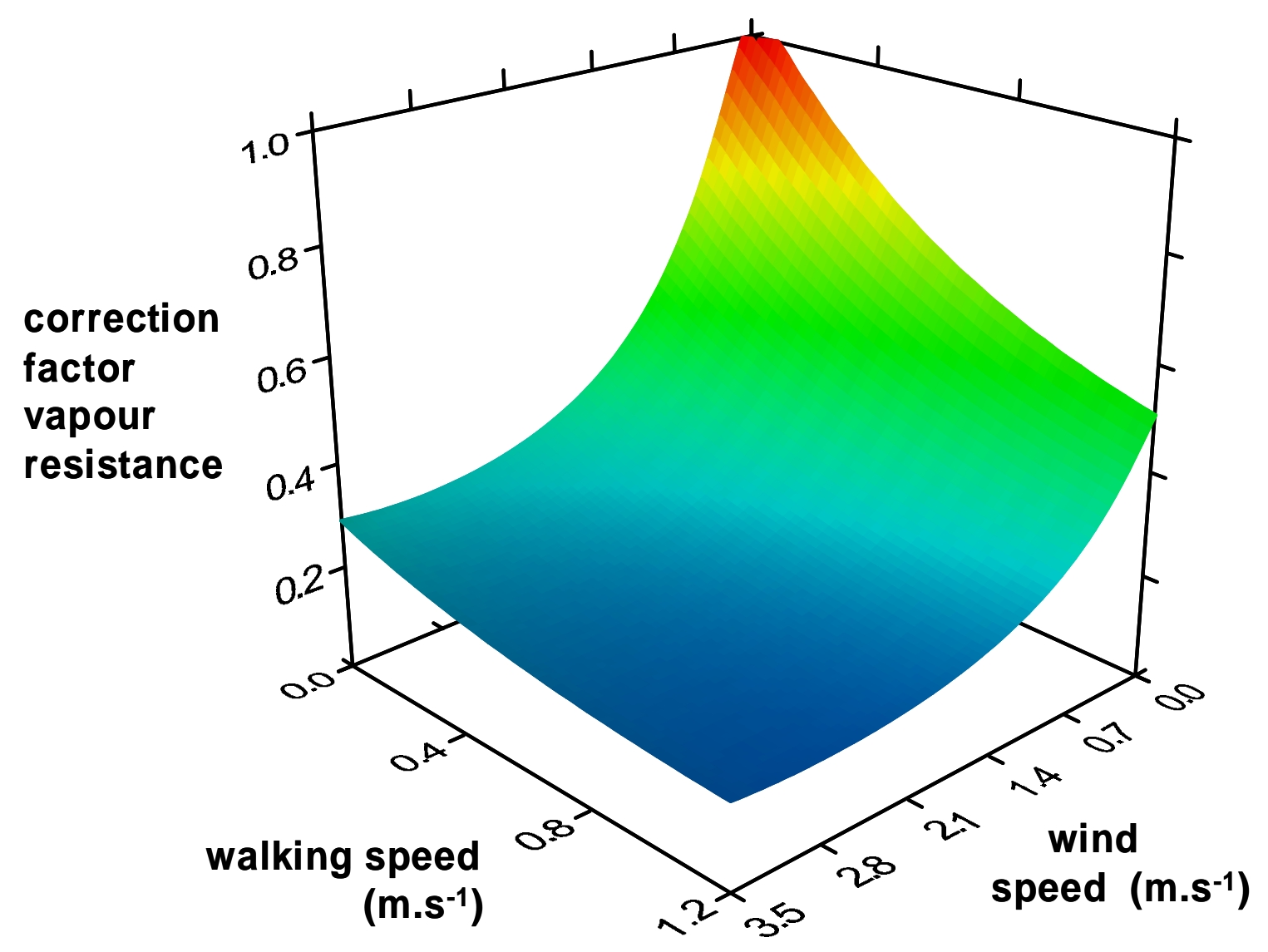

Heat Balance when wearing clothing, Figure 9 of 10 

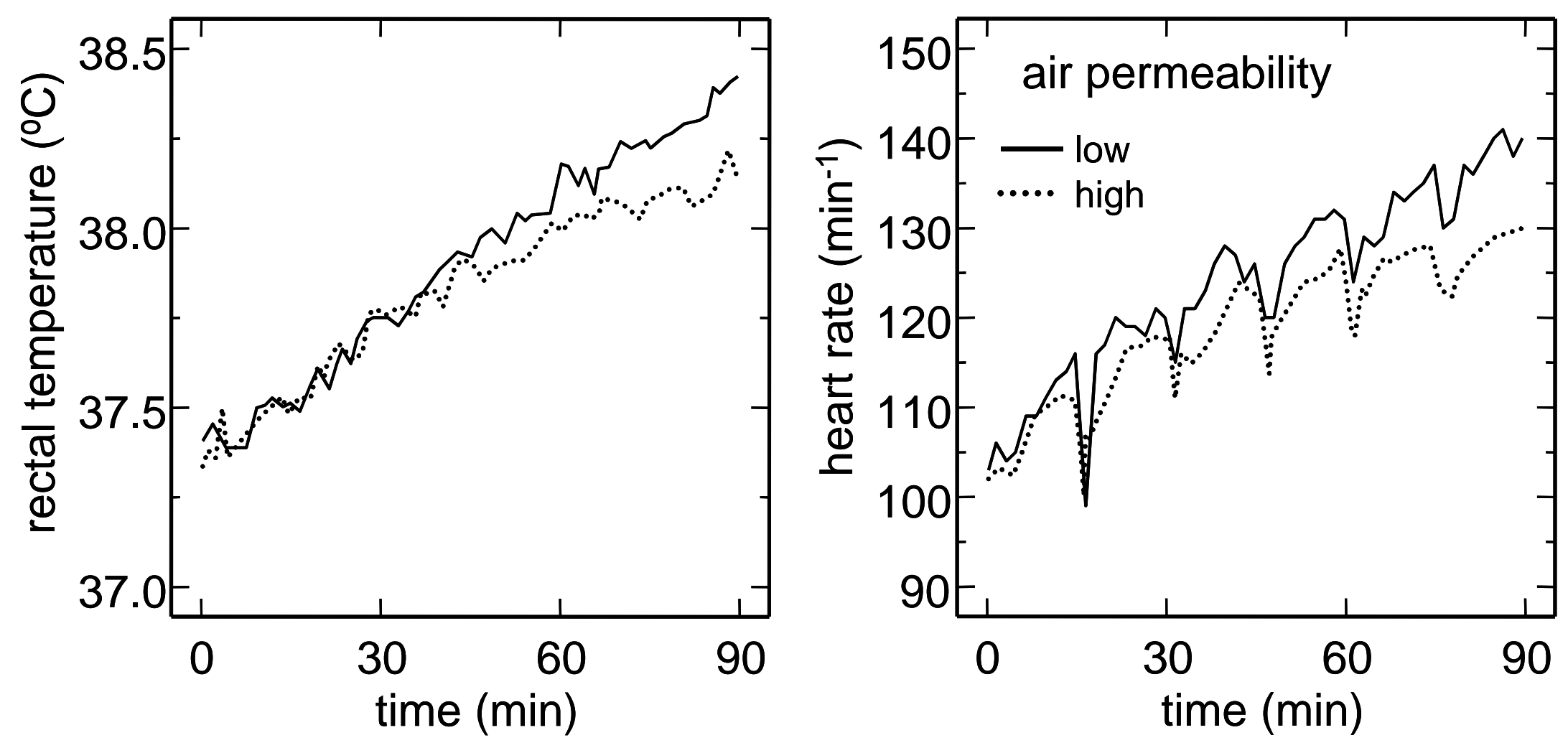